\title{
Problems with Fineness Testing of Coal Fly Ash for Use in Concrete
}

by Toy S. Poole

Structures Laboratory

Approved For Public Release; Distribution Is Unlimited

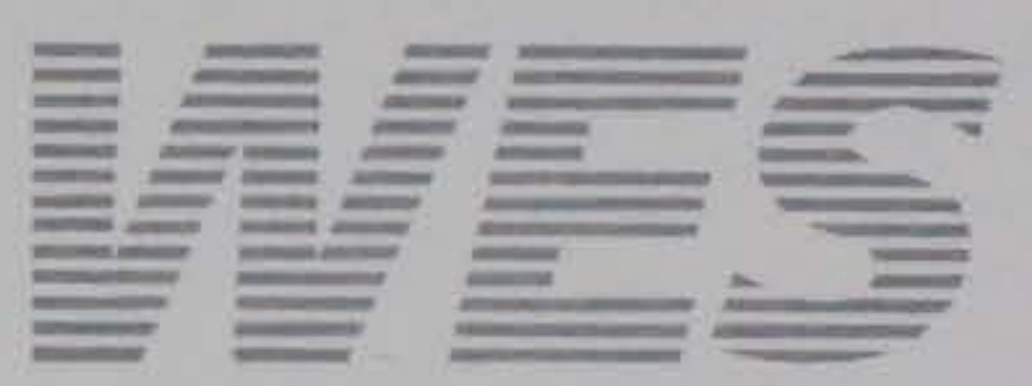

\author{
RESEARCH LIBRARY \\ US ARMY ENGINEER WATERWAYS \\ EXPERIMENT STATION \\ VICKSBURG, MISSISSIPPI
}


$28884^{99^{2}}$

Miscellaneous Paper SL-93-9

September 1993

\section{Problems with Fineness Testing of Coal Fly Ash for Use in Concrete}

by Toy S. Poole

Structures Laboratory

U.S. Army Corps of Engineers

Waterways Experiment Station

3909 Halls Ferry Road

Vicksburg, MS 39180-6199

Final report

Approved for public release; distribution is unlimited 


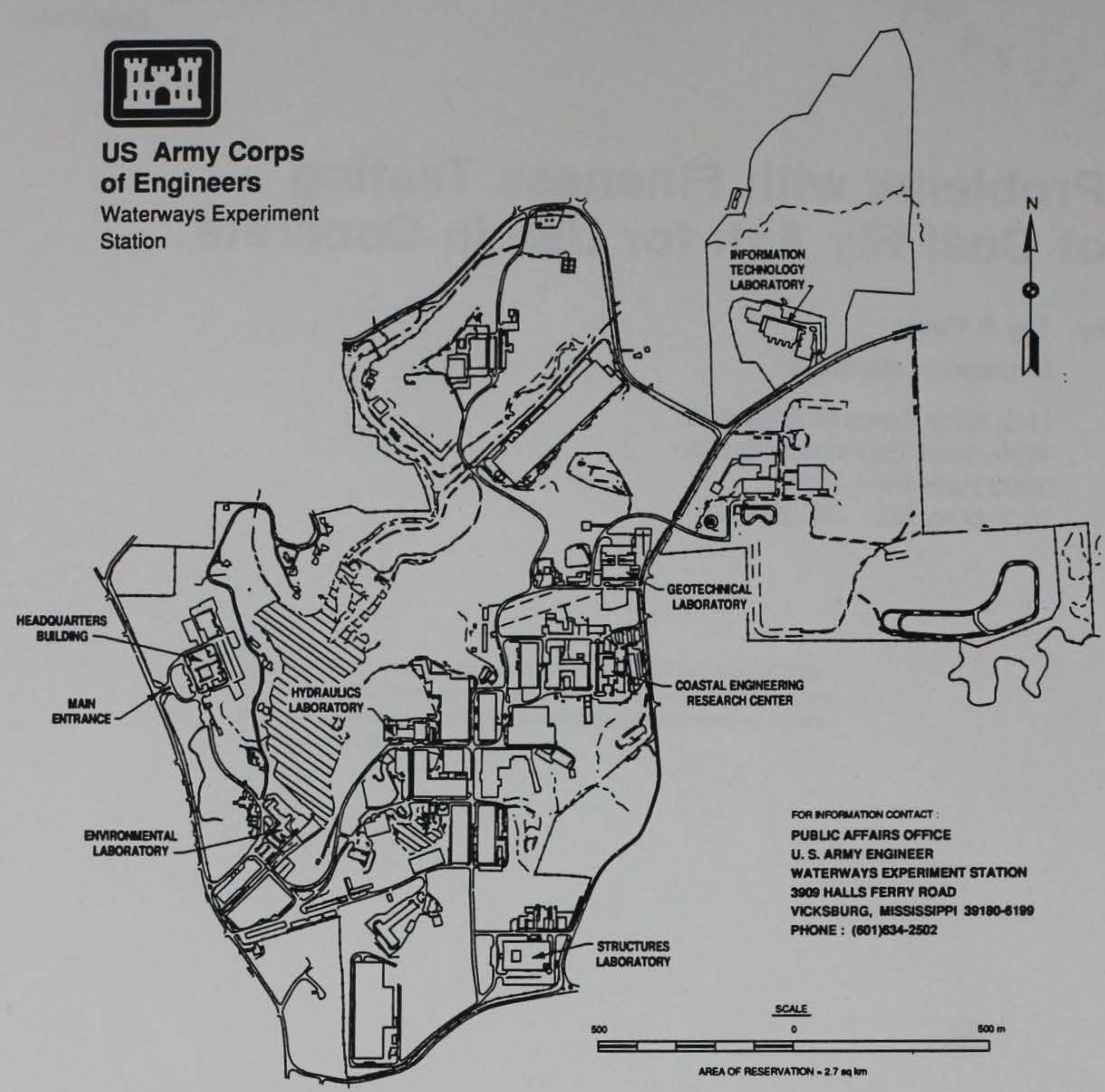

Waterways Experiment Station Cataloging-in-Publication Data

Poole, Toy S. (Toy Spotswood), 1946-

Problems with fineness testing of coal fly ash for use in concrete / by Toy S. Poole ; prepared for U.S. Army Corps of Engineers.

26 p. : ill. ; $28 \mathrm{~cm}$. - (Miscellaneous paper ; SL-93-9)

Includes bibliographical references.

1. Fly ash - Testing. 2. Concrete - Additives - Testing - Evaluation. 3. Particle size determination - Testing - Evaluation. I. United States. Army. Corps of Engineers. II. U.S. Army Engineer Waterways Experiment Station. III. Title. IV. Series: Miscellaneous paper (U.S. Army Engineer Waterways Experiment Station) ; SL-93-9.

TA7 W34m no.SL-93-9 


\section{Contents}

Preface $\ldots \ldots \ldots \ldots \ldots \ldots \ldots \ldots \ldots \ldots \ldots \ldots \ldots \ldots \ldots$ iv

1-Introduction $\ldots \ldots \ldots \ldots \ldots \ldots \ldots \ldots \ldots \ldots \ldots \ldots \ldots$

2-Fineness Uniformity $\ldots \ldots \ldots \ldots \ldots \ldots \ldots \ldots \ldots \ldots \ldots \ldots \ldots \ldots$

Relationship Between Fineness Uniformity Statistic

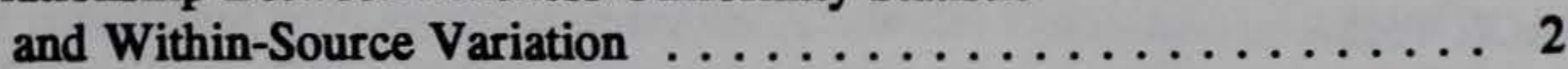

Effect of Sampling Procedures on Levels of Within-Source Variation . 3

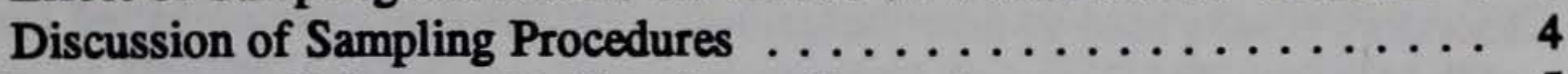

Importance of Fineness Uniformity on Strength $\ldots \ldots \ldots \ldots \ldots 5$

3-Evaluation of Butler and Kanare's Correction ........... 8

Calibration of $45-\mu \mathrm{m}$ Sieve $\ldots \ldots \ldots \ldots \ldots \ldots \ldots \ldots$

4-General Discussion and Conclusions $\ldots \ldots \ldots \ldots \ldots \ldots \ldots \ldots$

References $\ldots \ldots \ldots \ldots \ldots \ldots \ldots \ldots \ldots \ldots \ldots \ldots$

SF 298 


\section{Preface}

The work described in this report was conducted by the Structures Laboratory (SL), U.S. Army Engineer Waterways Experiment Station (WES) for the U.S. Army Corps of Engineers (USACE) under Civil Works Investigational Study Work Unit 32680, "Relating Variations in Properties of Cements and Pozzolans to Changes in Concrete." Dr. Tony Liu (CECW-EG) was the USACE Technical Monitor.

Laboratory results used to describe grab-sample variation were collected as part of the Cement and Pozzolan Acceptance Program (ER 1110-2-2000). Cement and Concrete Reference Laboratory (CCRL) data were provided by Mr. Robin Haupt, CCRL. Toy S. Poole, Concrete Technology Division (CTD), SL, was Principal Investigator and prepared this report.

All work was conducted under the general supervision of Mr. Bryant Mather, Director, SL; Mr. James T. Ballard, Assistant Director, SL; and Mr. Kenneth L. Saucier, Chief, CTD, SL.

Dr. Robert W. Whalin was the Director of WES. Commander was COL Bruce K. Howard, EN. 


\section{Introduction}

The fineness of fly ash, defined by ASTM Specification C 618 as the percentage retained on a $45-\mu \mathrm{m}$ sieve, when tested using ASTM Method C 430 , is a useful property with which to evaluate fly ash for use in portlandcement concrete. It replaced Blaine fineness for this purpose because of a better correlation with concrete strengths (Lane and Best 1982). Currently, C 618 specifies a limit on the maximum amount retained of 34 percent and a limit on the maximum variation in fineness of \pm 5 percent from the mean fineness of the last 10 samples. In testing experience at WES, the variation requirement is the most frequent cause of fly ash failing to meet requirements. This may be partly due to differences in sampling practices between suppliers and acceptance testing laboratories. Most fly ash suppliers determine uniformity in fineness based on some level of composite sampling. Acceptance testing is often done on grab samples, which inherently reflect more variation in the material. Another serious problem is disagreements in measured values of fineness between laboratories, particularly for very coarse fly ashes. The purpose of this report is to examine these two problems and to make recommendations for improvements.

Part 1 of the report analyses the requirement on variation in fineness. The approach is to determine whether the $\mathbf{5}$ percent uniformity requirement is reasonable given the within-source variation of sources believed to be of good quality. Part 2 of the report evaluates a modification to the fineness determination procedure. Butler and Kanare (1989) report that the procedure in ASTM C 430 causes a bias when applied to some fly ashes. They propose an alternative procedure, which is evaluated from Cement and Concrete Reference Laboratory (CCRL) interlaboratory test data. 


\section{Fineness Uniformity}

\section{Relationship Between the Fineness Uniformity Statistic and Within-Source Variation}

Fineness uniformity, as described by ASTM C 311, is directly related to the within-source standard deviation among samples. This relationship is developed below and then used as a tool for evaluating fly ash sources.

The specification requirement for fineness uniformity can be expressed mathematically as follows.

$$
D=\bar{x}_{10}-x_{i}
$$

where $\mathrm{D}$ is the maximum difference between the mean of the previous ten samples $\left(\overline{\mathbf{x}}_{10}\right)$ and the value for the sample currently under test $\left(\mathbf{x}_{i}\right)$. This requirement is set at 5 percent by $C 618$. In order to estimate the frequency with which $D$ will exceed the 5 percent requirement, the variance in $D\left(s_{D}^{2}\right)$ must be determined. The variance for a given source is related to the withinsource variance among samples $\left(\mathrm{s}^{2}\right)$, as follows:

$$
s_{D}^{2}=\frac{s^{2}}{10}+s^{2}=1.1 s^{2}
$$

The standard deviation, $s_{\mathrm{D}}$, is then

$$
s_{D}=1.05 s
$$

Two standard deviations will include 95 percent of expected values of D, i.e.

$$
2 s_{D}=2.10 s
$$

The value of within-source standard deviation that would result in $D$ being less than or equal to 5 percent in 95 percent of cases is: 


\section{$2.10 s \leq 5 \%$ \\ $s \leq 2.38 \%$}

Therefore, sources whose standard deviation among samples is greater than 2.38 percent are expected to exceed the $C 618$ requirement more than 5 percent of the time. If within-source standard deviation is dependent on sampling procedures, then these procedures must be strictly defined to avoid compliance disputes between producers and users.

\section{Effect of Sampling Procedures on Levels of Within- Source Variation}

There are considerable differences in sampling procedures underlying determination of fineness and fineness uniformity. Producers typically composite over large amounts of fly ash. Users typically use grab samples or composite samples representing smaller amounts of fly ash. It is important to know whether these differences have a significant effect on measures of within-source variation because of the effect of this statistic on the probability of compliance with the uniformity requirement.

Estimates of within-source variation based on composite sampling were obtained from fly ash suppliers' quality control data submitted twice a year to WES in support of the Corp of Engineers' qualified-source program. These data commonly represent samples composited from 2,000 tons of production or more ${ }^{1}$, representing a week or more of production. Twenty-six sources were included in this data set. A standard deviation was calculated from differences between sequential pairs of data (Taylor 1990). Such a calculation allows a certain amount of long-term change in the properties of the product without being reflected in a short-term measure of product uniformity.

Estimates of within-source variation based on grab sampling were taken from WES test data. Eighteen of the sources described above had been tested frequently enough at WES during acceptance testing for larger construction projects to allow reasonable estimates of within-source variation. Relative to producer's compositing practices, these data represent grab samples and are identified as such in sampling guidance, although, in fact the practice is to take two grab samples from a single delivery truck or rail car and to blend them to make a test sample. Within-source standard deviations were calculated as with the producers' data.

1 The relevant Specification, ASTM C 618 cites ASTM Methods C 311 for sampling requirements, C 311 requires that any sample tested for fineness not represent more than 400 tons. 
Table 1 summarizes the observed values of within-source standard deviation, both from supplier's data, which generally represents some level of compositing, and from WES test data, which represents essentially grab samples. The two measures of product variability differ substantially. The effect of sampling on estimates of within-source variation is illustrated in Figure 1. The mean value for within-source standard deviation from composite-sampled data is 1.6 percent, with all but one source falling below 3 percent. Six of the twenty-six sources ( 26 percent) exceed the critical value of 2.38 percent developed above.

The mean within-source standard deviation for the grab-sample data is 3.1 percent, with three sources exceeding 4 percent. Ten of eighteen (56 percent) of these sources exceed the critical value of 2.38 percent. The standard deviation in some sources, when measured from grab samples, is high enough that a substantial frequency of failures would be expected. Table 1 summarizes the expected frequency of failures, based on a purely statistical extrapolation of the within-source standard deviation, and compares them with the observed frequency. Summed over all eighteen sources, the total number of expected failures is 60.9 . The observed number is 55 , which is not statistically different $\left(\mathrm{X}^{2}=0.55,1 \mathrm{df}, \mathrm{P}>0.50\right)$.

The conclusion to be drawn from this analysis is that the high number of specification failures in the fineness uniformity property are expected given the size of the within-source variation common to many fly ash sources when sampled by grab samples. These fly ash sources are commonly used by the Corps of Engineers and are believed to perform satisfactorily.

\section{Discussion of Sampling Procedures}

The result of the forgoing analysis is that type of sampling, composite vs. grab, is an important factor in determining likelihood of compliance with specification requirements. ASTM C 311 gives no guidance on sampling except that it allows a sample to be either composite or grab, and it should not represent more than $\mathbf{4 0 0}$ tons of fly ash. The composite sampling practiced by some fly ash producers probably exceeds the limit of 400 tons per sample. If grab sampling is to remain a legitimate sampling technique for monitoring uniformity, then either the specification limit must be increased or some producers must reduce the variability of their product.

Some consideration should be given to the information obtained from different sampling procedures. From an engineering standpoint, it is important that the sampling reflect something about material properties that is meaningful to people concerned about concrete quality control. A grab sample will reflect the maximum level of variation in a product. If variation among concrete batches is of concern, then grab sampling may most closely reflect the corresponding variation in fly ash. However, if uniformity over larger amounts of concrete is of interest, grab sampling may be meaningless. In this 
case, some averaging of the property is of more interest, suggesting some level of composite sampling.

Concrete quality-control tests are required, according to $\mathrm{ACI} 318$, at a minimum of one per $150 \mathrm{yd}^{3}$ of concrete. This could represent as much as about 20 tons of fly ash (at a usage rate of $250 \mathrm{lb} / \mathrm{yd}^{3}$ of concrete). There is an argument then to be made that a sample ought to represent the variation that could occur among 20-ton lots of material. However, if a producer were required to supply and certify test results showing compliance with $C 618$ when using C 311 procedures, it is to be assumed he would designate 2,000ton units of production as manufacturing lots, sample either by continuous sampling and compositing or by a single grab sample representing each 400 tons, make the five tests required by C 311 to be done for each 400 tons, composite the five and make all other tests on the composite representing the 2,000-ton lot. Assuming this scenario, the producer will have a fineness value for each 400 tons of production. Neither C 618 nor C 311 state whether the values compared for uniformity are on 400 -ton or 2,000 -ton increments of production. In any case, the sample represents considerably more than 20 tons.

It is probably possible to argue for the efficacy of quite a number of sampling procedures, however, in practice, using agencies will find it somewhat cumbersome to do anything other than take grab samples. Composite sampling programs require more work and attention to detail than is probably reasonable to expect. Given this practical reality the state of current fly ash collection practices and technology, it is probably necessary to relax the specification requirement on fineness uniformity.

The following analysis investigates the effect on strength variation of relaxing the fineness uniformity requirement.

\section{Importance of Fineness Uniformity on Strength}

The effect of changes in fly ash fineness on properties of concrete containing fly ash has both direct and indirect components. The most obvious direct effect is that a coarsening of the material results in an apparent relative retardation in strength gain, i.e. the 1-day or 3-day strength of concrete is lower. Assuming that the observed coarsening is due merely to failure of the fly ash collection system to collect as many of the fine particles as it did previously rather than being due to contamination with coarse particles of different composition, it is not true that the reaction is going any slower, it is merely that there is less surface area for reaction per unit mass. Indirect effects include effects on workability, air content, water requirement, and perhaps admixture dosage. The compensation that may be required to adjust for some of these effects may, in turn, affect strength. However, the most likely compensating action would be either to increase cement content or increase water-reducing admixture dosage to achieve a lower water-cement ratio at constant slump to restore previous levels of early strength. 
In order to gain some insight into the direct effect of fineness uniformity on strength, fineness was analyzed against the pozzolanic activity index (PAI), as described in ASTM C 311-88. This is a test that compares strength of a portland cement-fly ash mortar to the strength of the equivalent portlandcement mortar. Fly ash represents 35 percent of the cementitious material, by volume. Results are expressed as a percentage of control. Water content of both mortars is adjusted to a constant flow, so the indirect effect of fineness on water demand is accounted for. Strengths are measured after 28 days of curing at $100^{\circ} \mathrm{F}$, consequently, this test best measures relatively long-term strength-development potential of materials. A subsample of the WES test data described above was also used to perform this analysis. These data were chosen from sources that represented extremes in fineness as well as from some that represented the more common intermediate values. Six sources were represented. The PAI test conducted at $38^{\circ} \mathrm{C}\left(100^{\circ} \mathrm{F}\right)$ was a requirement of C 618 and C 311 in 1988. It is not included at present. The data obtained from it are regarded as useful for the purposes of this report.

Ravina (1980) did a similar analysis based on fly ash collected from various precipitator fields of in a single source. Fineness varied from 9.7 percent to 35 percent.

Results from both sets of data are presented in Figure 2. The WES data shows considerable scatter about the linear regression line, due to effects of different cements and fly ashes, as well as to other unidentified sources of systematic error, and to random testing error. The slope of the regression line indicates that, on the average, one should expect a decrease in PAI of about 1.2 percent for every 1 percent increase in fineness. The Ravina data shows less error about its regression line, due probably to the better control on materials used in testing. The slope of this regression indicates a decrease in strength of 2.1 percent for every 1 percent increase in fineness. The average slope from the two analyses is 1.6 percent.

Within the limits of the fineness-uniformity specification requirement of 5 percent, a 7 percent difference in the fineness of two consecutive grab samples is a probable event. The analysis indicates that this could result in a PAI change of about 11 percent. For 4,000-psi mortar, this represents a change of $440 \mathrm{psi}$. This is not a particularly large number with respect to testing error associated with strength testing. However, with a more liberal 10 percent uniformity requirement, a maximum probable change in fineness could result in a PAI change of as much as 22 percent between two consecutive samples, or 880 psi for the 4,000 -psi mortar, which represents a considerable change. However, changes of this magnitude are sometimes acceptable within the limits of C 618 requirements. For example, a shift of PAI from 100 percent to 78 percent is allowable, given the lower limit on PAI of 75 percent.

The foregoing arguments result in a dilemma. The existing variation in commonly used fly ashes is such that a $\mathbf{5}$ percent limit on fineness variation is unrealistic, but a relaxed requirement of 10 percent, which would allow all of these sources to comply, apparently permits variation in strength that may be objectionable. However, no evidence was found of cases in which variation 
in fly ash was actually related directly to excessive variation in concrete strength. At least two things could account for this. First, the effect of fly ash fineness on strength, as measured by the PAI, may not accurately reflect the condition in concrete. Second, changes in strength of concrete when mixture proportions are constant is a result of variation in quite a number of factors. If this variation is at least approximately random, there will often be a tendency for compensating variation to occur which will disguise the effect of variation in a single variable.

Given the apparent absence of a field problem, it is probably reasonable to allow relaxation of the uniformity requirement to 10 percent. It would be desirable to focus some research attention on the problem whether this a real concrete problem. 


\section{Evaluation of Bulter and Kanare's Correction}

\section{Calibration of $45-\mu \mathrm{m}$ Sieve}

The determination of fineness by method C 311 directs the use of procedures in C 430 to calibrate the $45-\mu \mathrm{m}$ sieves. This method directs that a correction factor (CF) be calculated based on the nominal value of a Standard Reference Material (SRM) cement fineness standard to the measured residue of that standard:

$$
C F_{C 430}=\frac{[\text { nominal } S R M \text { residue }- \text { measured residue] }}{\text { measured residue }} \times 100
$$

This correction factor is then added to the measured fineness of an unknown sample to give the test result.

Butler and Kanare (1989) have analysed sieve corrections and determined that the correction factor should be determined by the simple difference between the nominal value and the measured residue of the SRM:

$$
C F_{B X}=[\text { nominal } S R M \text { residue-measured residue }] \times 100
$$

The final test result is then calculated by adding the correction factor to the measured fineness. Butler and Kanar's correction results in a smaller CF for a given difference in nominal and measured residue.

The effect on the final test result of the difference between these two correction procedures is very small when little sieve correction is needed, or when fineness of an unknown is close to the fineness of the SRM used to correct the sieve. The effect becomes substantial as the size of the correction factor becomes large or when the fineness of an unknown is much different from the fineness of the SRM.

The nominal $45-\mu \mathrm{m}$ sieve residue for SRM fineness standards is about 10 percent, so the test results on fly ashes whose fineness is with a few percent of this value are not seriously affected by the method for calculating the 
correction factor. But the specification limit for fineness of fly ash is 34 percent and many fly ashes are consistently close to this limit. At this level, the method of calculating a correction factor can have significant effects of test results.

The Cement and Concrete Reference Laboratory (CCRL) fly ash proficiency sample numbers 7 and 8 were selected because of their relatively coarse particle size. Thirty-eight laboratories provided enough information to compare test results calculated from the $\mathrm{C} 430$ correction procedure and the Butler-Kanare correction procedure.

The results of the comparison are summarized in Table 2. The choice of correction procedures resulted in different measures of fineness. The C 430 procedure resulted in fineness values that were about 4 percent higher than calculated using the Butler-Kanare procedure. Analysis of the C 430 correction factors showed that the final test result was strongly dependent on the size of the correction factor (Figures 3 and 4). Figure 5 shows the frequency distribution of C 430 correction factors from the $\mathbf{3 8}$ laboratories. There is clearly a predominance of correction factors greater than 100 (sieves with openings greater than $45 \mu \mathrm{m}$ ). This bias, plus the dependence of the reported test result on the size of the correction factor, results in a significant bias in measured fineness towards higher values if sieves are randomly chosen.

Fineness results calculated using the Butler-Kanare correction factor showed no evidence of dependence on the size of the correction factor (Figure 6 and 7). Therefore, the fact that most sieve cloth has openings larger than $45 \mu \mathrm{m}$ is not critical.

A comparison of the between-laboratory standard deviation associated with test results obtained from the two procedures showed that the Butler-Kanare procedure resulted in smaller values. This reduction in testing variation was highly significant in both samples (Table 2).

Expected differences between laboratories analyzing the same material are expressed as $d 2 \mathrm{~s}^{1}$ values (ASTM C 670). This value represents a maximum difference expected in 95 percent of comparisons of single results between two laboratories. Using the correction procedure in C 430 and standard deviations from the CCRL data, the $\mathrm{d} 2 \mathrm{~s}$ is 13.1 percent. Using Butler and Kanar's procedure, the $\mathrm{d} 2 \mathrm{~s}$ is 7.1 percent. This represents a significant improvement in between-laboratory agreement, but the D2S still needs to be lower.

Making a test result the mean of several replicate determinations is one way to reduce between-laboratory variation without doing anything else to the test method. Defining a test result to be the mean of three independent determinations (to include different sieves) reduces the d2s to 4.1 percent. A d2s of 2.2 percent can be realized by taking a mean of ten independent determinations. Given the simplicity of the test, it is reasonable to require that a referee test result be made to be the mean of three determinations.

1 In ASTM C 670, "d2s" is "acceptable difference between two results on test portions of the same material." 


\section{General Discussion and Conclusions}

The analysis of the fineness uniformity problem clearly indicates that, if the requirement to be retained in $\mathrm{C} 618$, then adjustments to guidance are necessary. These include sampling guidance, and some consideration to tolerable levels of variation. The current requirements are often not consistent with current producer or user practice.

Another practical problem with the uniformity requirement not discussed previously is that users often purchase and test fly ash from a source on an intermittent basis. This is particularly true for small construction projects, but may also be true to some degree on large construction projects. This means that a user's test data may reflect variation in the fly ash that occurs over very long time periods and might be quite large, particularly if there has been a gradual change in the product over that time interval. In contrast, the producer's uniformity test data might reflect quite uniform material since it will be based on data collected over a relatively smaller time frame. Therefore, practically the only way that a producer can insure specification compliance would be for the testing to be based on composite samples taken over a long time period. However, this kind of procedure makes verification by the using agency very difficult because of the amount of sampling that must be done.

Relaxing the uniformity requirement for fineness from 5 percent to 10 percent would largely avoid these problems and bring specification requirements into conformance with current practice.

Adoption of the Butler and Kanare correction procedure for the determination of fineness would result in an important improvement in betweenlaboratory testing precision. 


\section{References}

American Society for Testing and Materials (ASTM). (1988). "Standard test methods for sampling and testing fly ash or natural pozzolan for use as a mineral admixture in portland-cement concrete, " Designation: C 311-88, Concrete and Aggregates 04.02, Philadelphia, PA.

. (1991). "Standard test method for fineness of hydraulic cement of the 45- $\mu \mathrm{m}$ (No. 325) sieve," Designation: C 430-90, Cement; Lime; Gypsum 04.01, Philadelphia, PA.

- (1991). "Standard practice for preparing precision and bias statements for test methods for construction materials, " Designation: C 670, Cement, Lime, Gypsum 04.01, Philadelphia, PA.

. (1992). "Standard specification for fly ash and raw or calcined natural pozzolan for use as a mineral admixture in portland cement concrete," Designation: C 618-92a, Concrete and Aggregates 04.02, Philadelphia, PA.

Butler, W. B., and H. M. Kanare. (1989). "Testing fly ash for fineness to ASTM C 430: Sieve calibration." Materials Research Society Symposium Proceedings 138, 107-112.

Lane, R. O. and J. F. Best. (1982). "Properties and use of fly ash in portland cement concrete." Concrete International/July 1982, 81-92.

Ravina, D. (1980). "Optimized determination of PFA (fly ash) fineness with reference to pozzolanic activity." Cement and Concrete Research 10, 573580.

Taylor, J. K. (1990). "Statistical techniques for data analysis." Lewis Publishers, Chelsea, MI. 


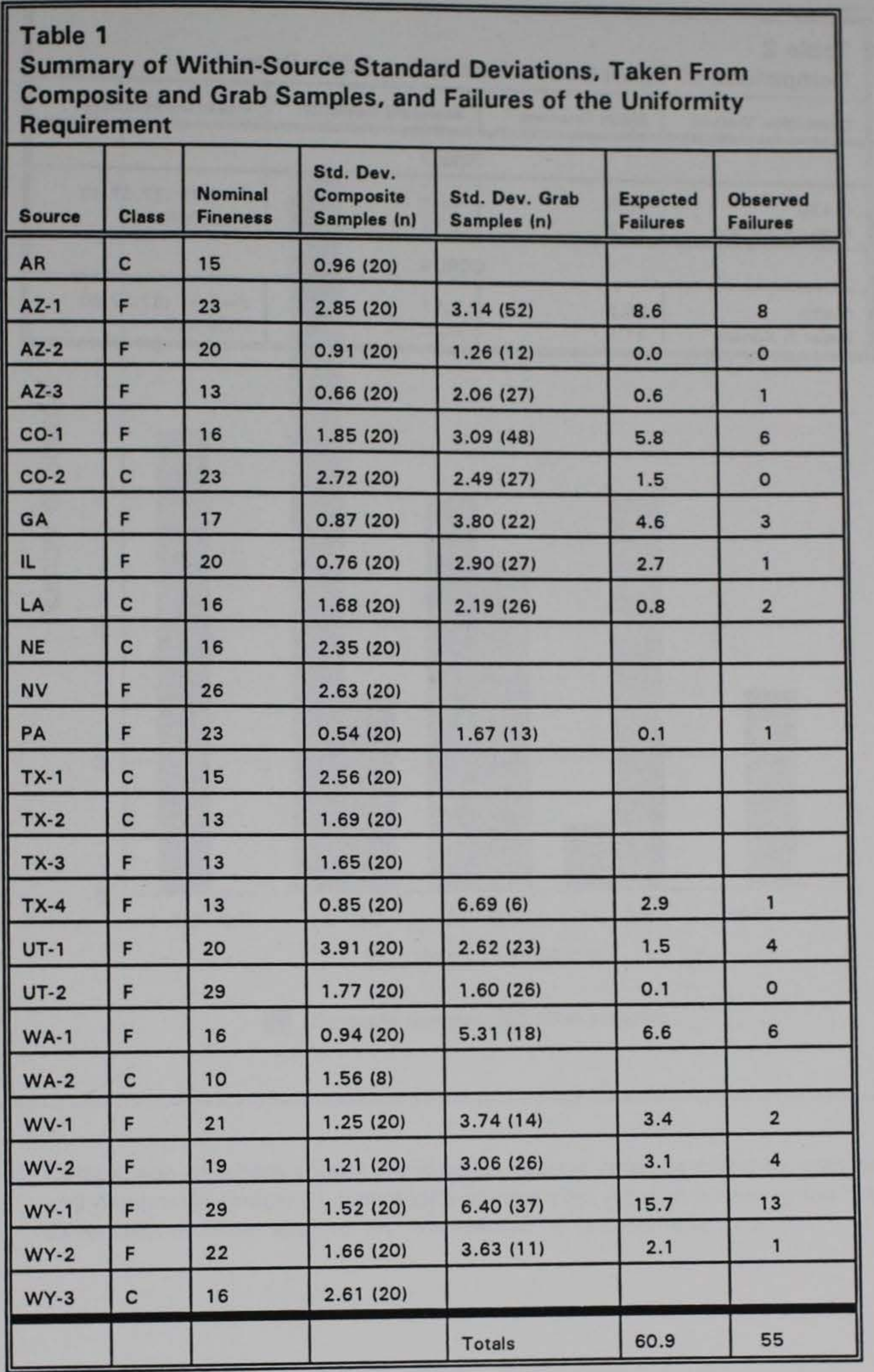




\begin{tabular}{|c|c|c|c|}
\hline \multicolumn{4}{|c|}{$\begin{array}{l}\text { Table } 2 \\
\text { Comparison of Sieve Corrections Using CCRL Data }\end{array}$} \\
\hline Correction Method & Mean Fineness & Standard Deviation & F-test Comparison \\
\hline \multicolumn{4}{|c|}{ CCRL 7} \\
\hline $\begin{array}{l}\text { C } 430 \\
\text { Butler \& Kanare }\end{array}$ & $\begin{array}{l}30.3 \\
27.2\end{array}$ & $\begin{array}{l}4.02 \\
1.59\end{array}$ & $\begin{array}{l}F=6.39(37,37 \mathrm{df}) \\
P<0.005\end{array}$ \\
\hline \multicolumn{4}{|c|}{ CCRL 8} \\
\hline $\begin{array}{l}\text { C } 430 \\
\text { Butler \& Kanare }\end{array}$ & $\begin{array}{l}34.2 \\
31.1\end{array}$ & $\begin{array}{l}5.17 \\
3.20\end{array}$ & $\begin{array}{l}F=2.31(37,37 d f) \\
P<0.025\end{array}$ \\
\hline
\end{tabular}




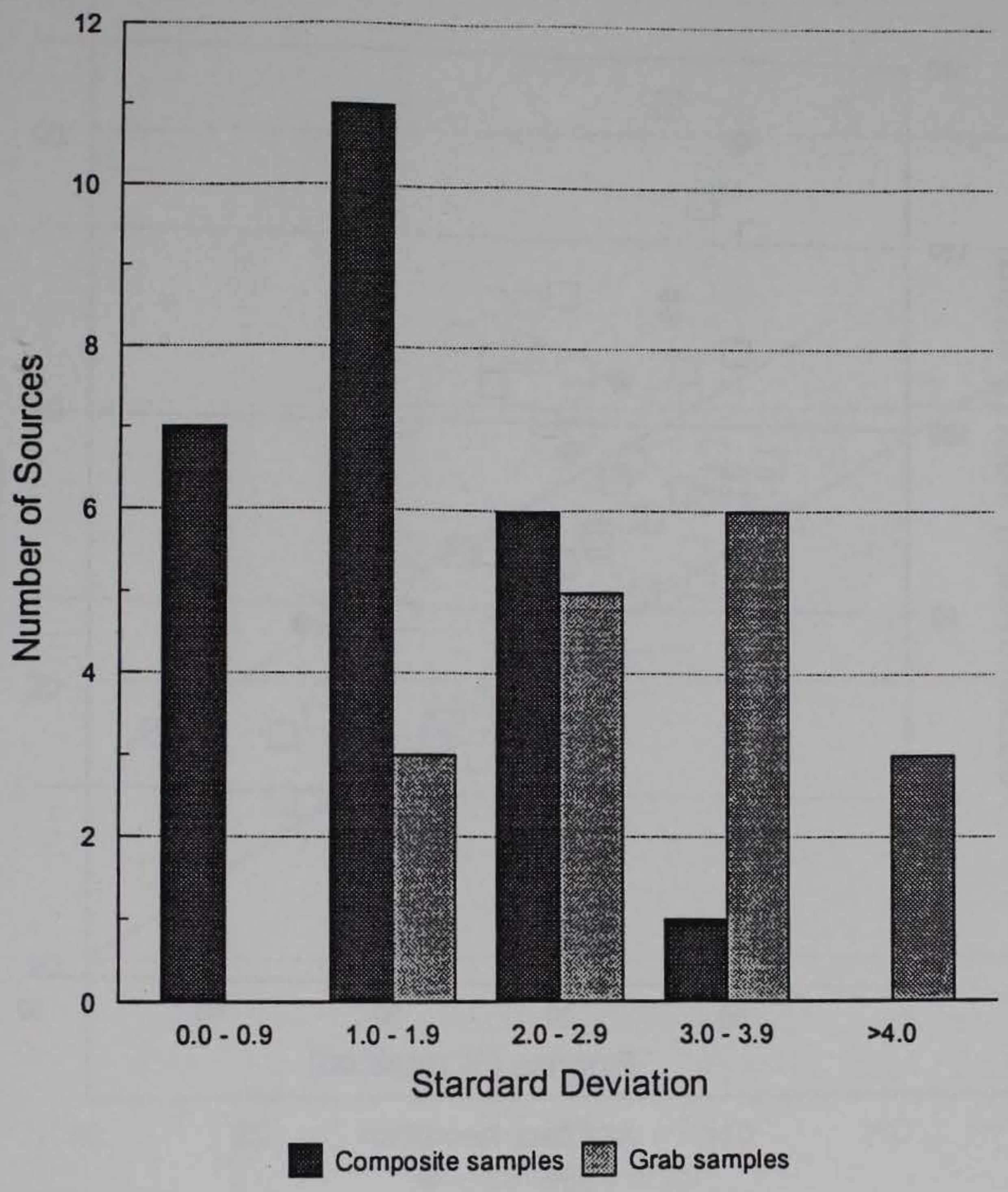

Figure 1. Comparison of within-source standard deviations when sampled by grab sampling and composite sampling. Composite-sample data represent twenty-five sources. Seventeen of these sources are represented by grab-sample data 


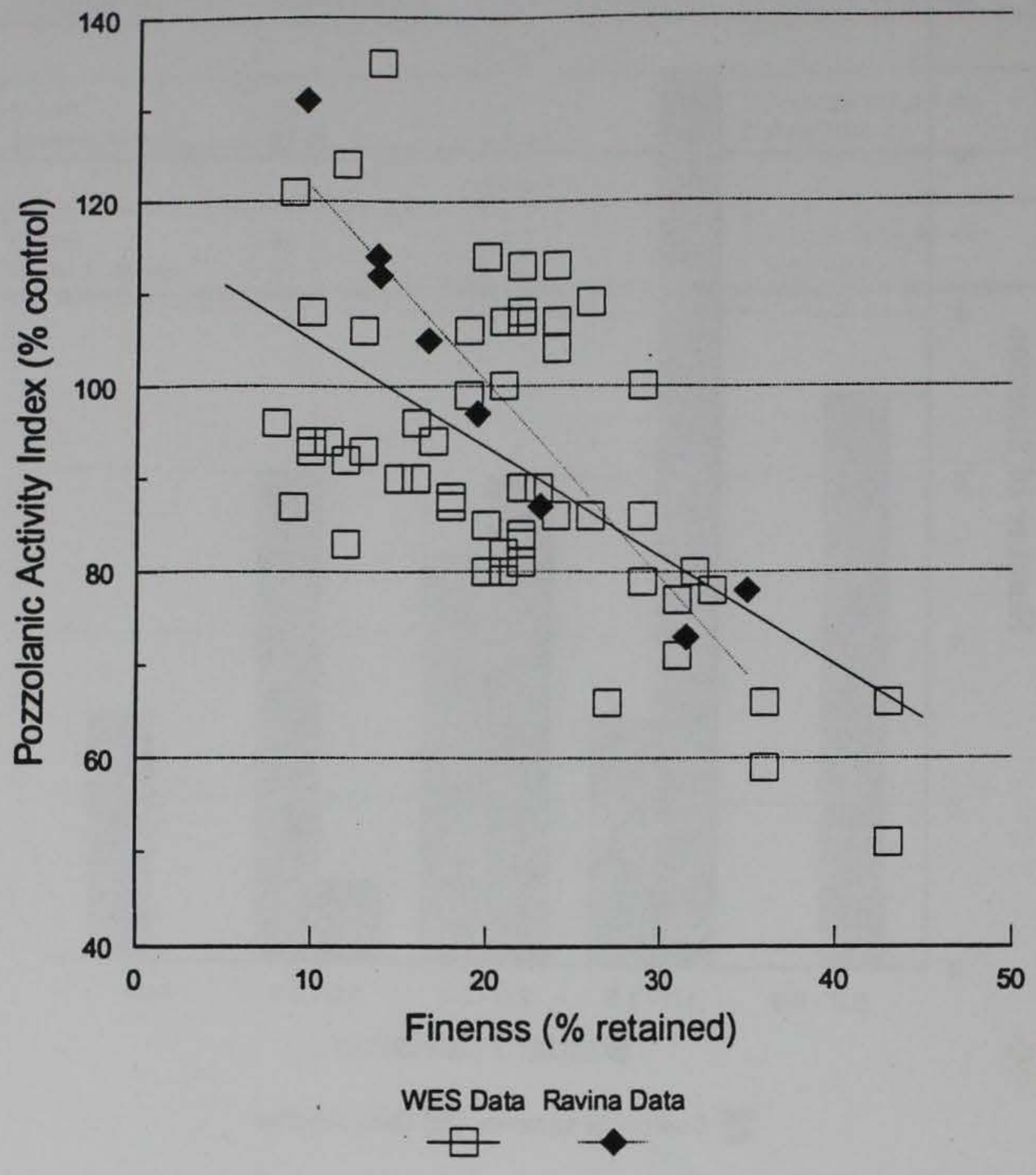

Figure 2. Effect of fineness ( $\%$ retained on a $45 \mu$ sieve) on pozzolanic activity index 


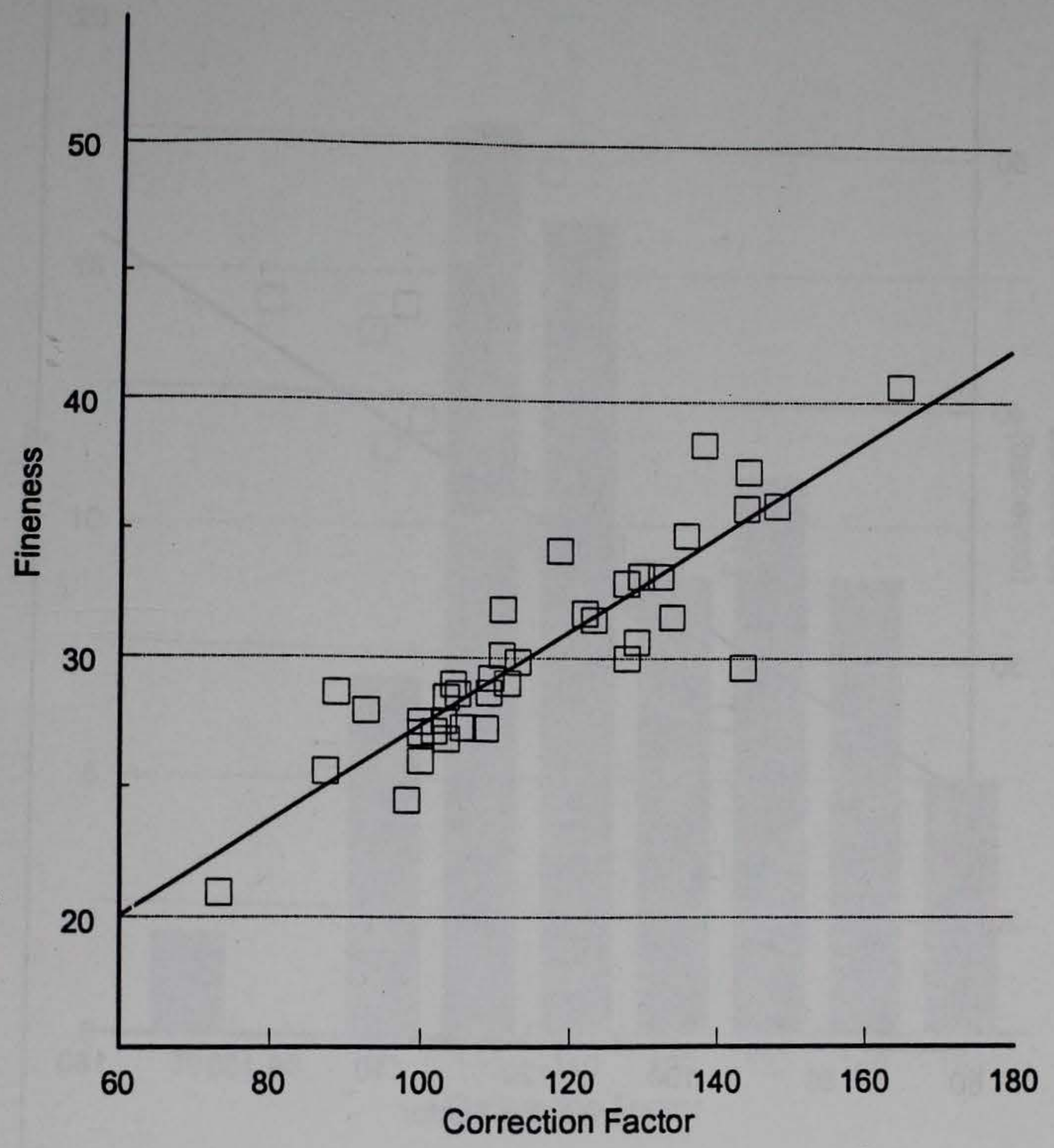

Figure 3. Effect of size of sieve correction factor on determination of fineness of CCRL 7 by ASTM C 430 


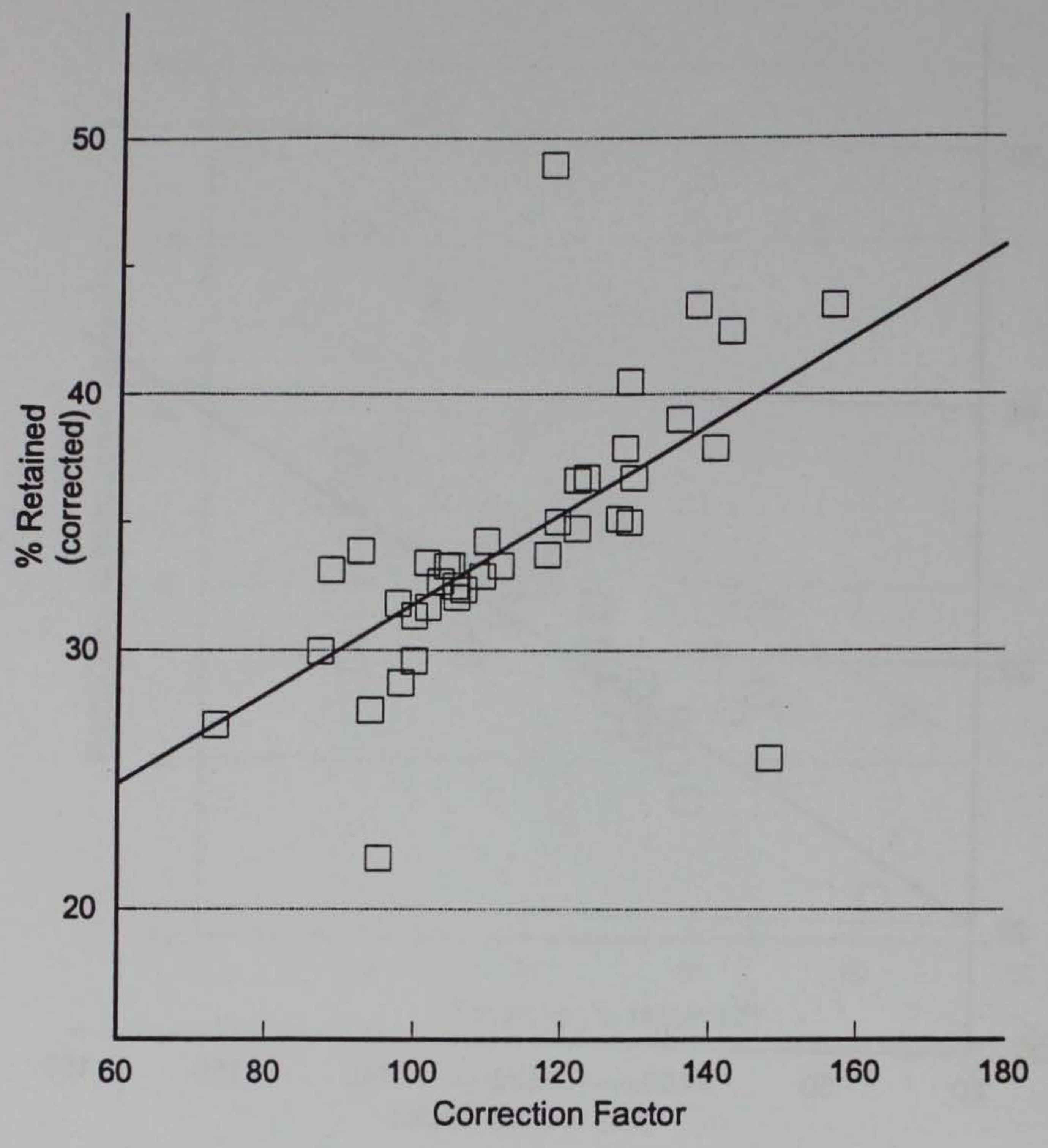

Figure 4. Effect of size of sieve correction factor on determination of fineness of CCRL 8 by ASTM C 430 


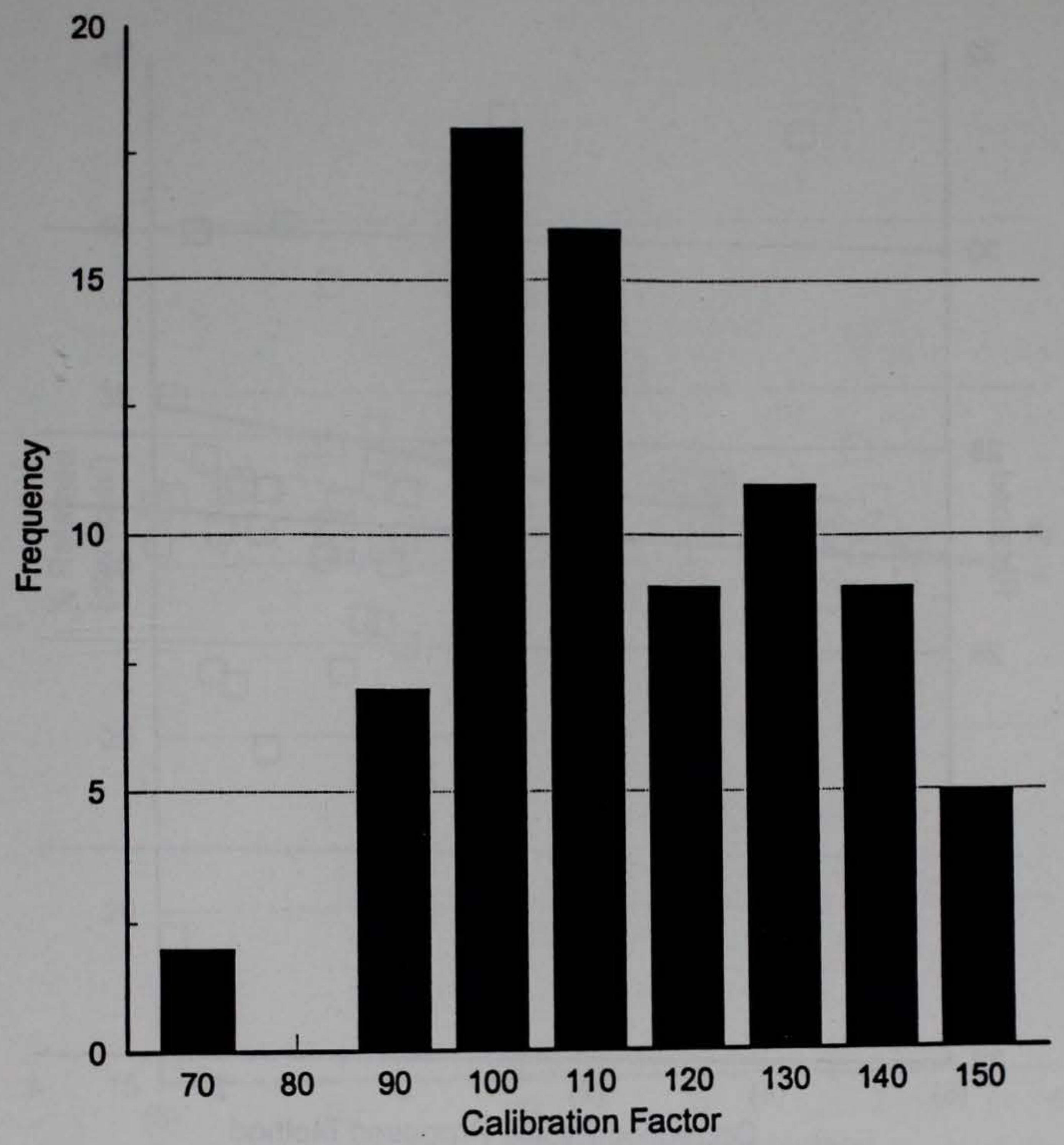

Figure 5. Frequency distribution of C 430 sieve correction factors reported by CCRL as used in measuring fineness of samples CCRL 7 and 8 


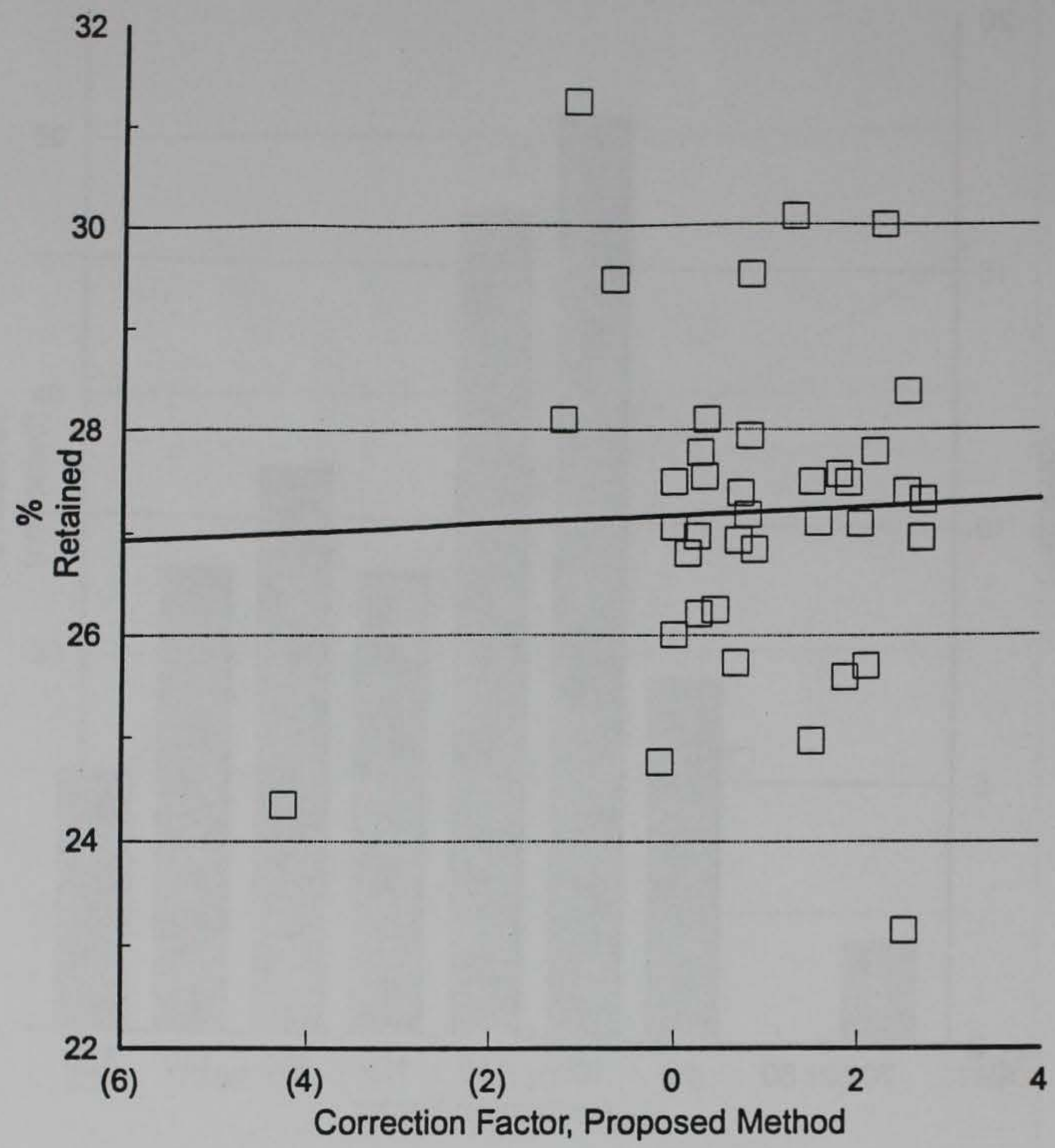

Figure 6. Effect of size of sieve correction factor on determination of fineness of CCRL 7 by the Butler and Kanare method 


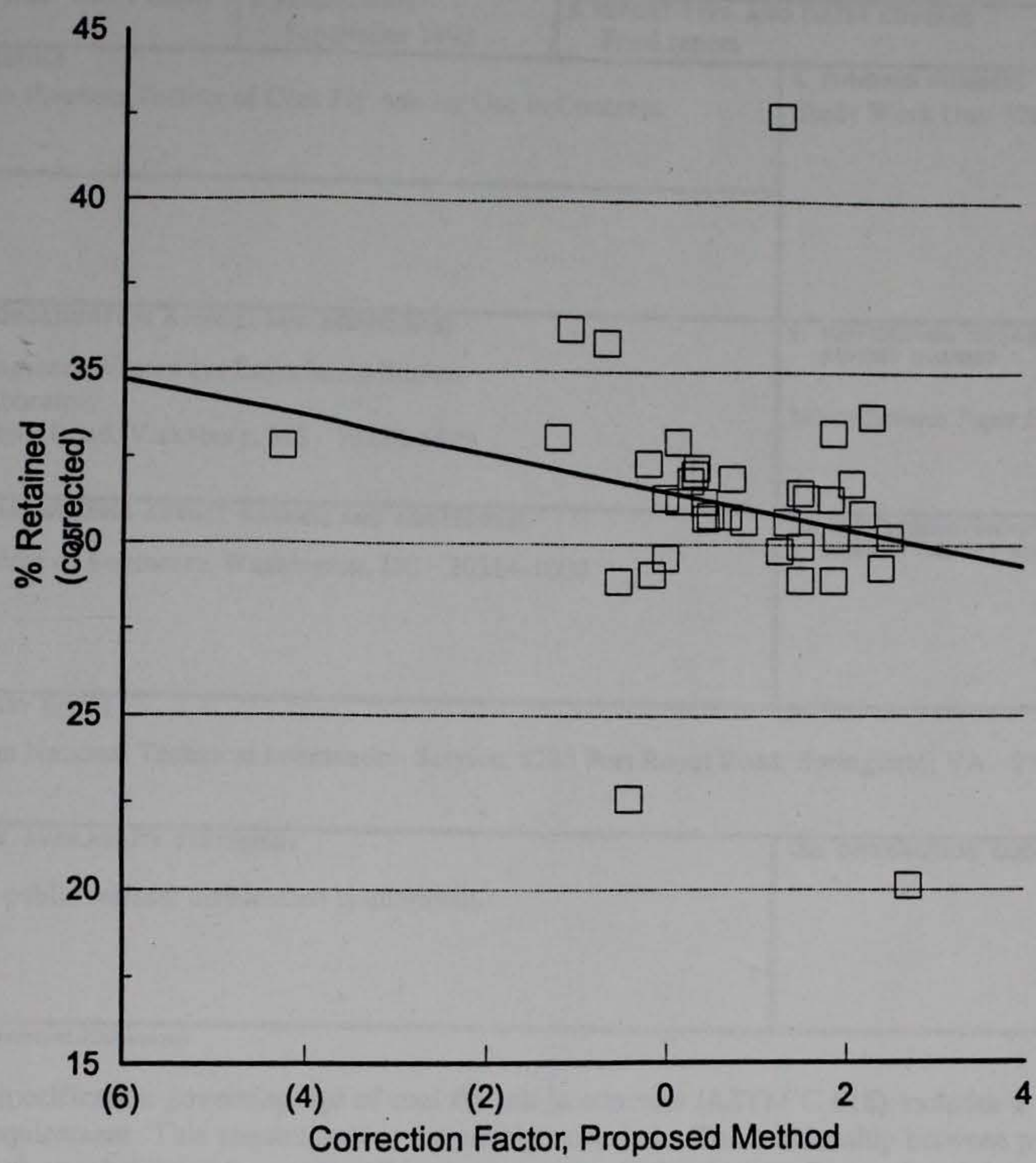

Figure 7. Effect of size of sieve correction factor on determination of fineness of CCRL 8 by the Butler and Kanare method 


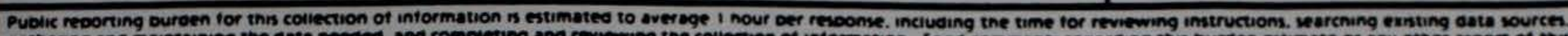
gathering ano maintaining the cata needed. and comoleting and reviewing the coliection of intormation. Send comments regarding this burden estimate or any other aspect of this coliection of intormation,

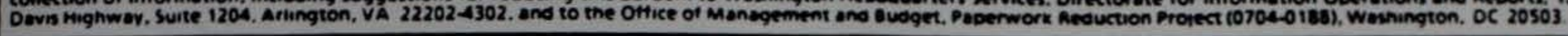
1. AGENCY USE ONLY (Leave Blank) 2. REPORT DATE
September 1993
3. REPORT TYPE AND DATES COVERED
Final report

4. TITLE AND SUBTITLE

Problems with Fineness Testing of Coal Fly Ash for Use in Concrete

5. FUNDING NUMBERS

Study Work Unit 32680

6. AUTHOR(S)

Toy S. Poole

\section{PERFORMING ORGANIZATION MAME(S) AND ADDRESS(ES)}

U.S. Army Engineer Waterways Experiment Station

Structures Laboratory

3909 Halls Ferry Road, Vicksburg, MS 39180-6199

9. SPONSORING/MONITORING AGENCY NAME(S) AND ADDRESS(ES)

U.S. Army Corps of Engineers, Washington, DC 20314-1000

8. PERFORMING ORGANIZATION REPORT NUMAER

Miscellaneous Paper SL-93-9
10. SPONSORING/MONITORING AGENCY REPORT NUMBER

\section{SUPPLEMENTARY NOTES}

Available from National Technical Information Service, 5285 Port Royal Road, Springfield, VA 22161.

\section{2a. DISTRIBUTION / AVAILABILITY STATEMENT}

12b. DISTRIBUTION CODE

Approved for public release; distribution is unlimited.

\section{ABSTRACT (Maximum 200 words)}

The specification governing use of coal fly ash in concrete (ASTM C 618) includes a finenessuniformity requirement. This requirement is frequently exceeded. The relationship between product variation and the probability of exceeding this requirement was developed. It was found that a product standard deviation in fineness (including testing error) of less than or equal to 2.38 percent would be required to ensure that a material would meet the uniformity requirement in 95 percent of samples. Product standard deviation is strongly dependent on sampling techniques. Many apparentlygood fly ashes fail to meet the C 618 level of uniformity when sampled by grab samples, but more meet the requirement when analysis is done on composite samples.

An error in the calibration of sieves used in the testing of fly ash fineness and a corrective action has been published. In this work, CCRL data collected on two very coarse samples were used to evaluate the improvement in testing error associated with the change. The between-laboratory standard deviation for the existing test method were found to be 4.6 percent. It was reduced to 2.4 percent when the new procedure was applied.

\begin{tabular}{|l|l|l|}
\hline $\begin{array}{l}\text { 14. SUBECT TERMS } \\
\text { Coal fly ash } \\
\text { Concrete }\end{array}$ & Fineness \\
\hline $\begin{array}{l}\text { 17. SECURITY CLASSIFICAFION } \\
\text { OF REPORT } \\
\text { UNCLASSIFIED }\end{array}$ & $\begin{array}{c}\text { 18. SECURITY CLASSIFICATION } \\
\text { OF THIS PAGE } \\
\text { UNCLASSIFIED }\end{array}$ & $\begin{array}{l}\text { 19. SECURITY CLASSIFICATION } \\
\text { OF ABSTRACT }\end{array}$ \\
\hline
\end{tabular}

